\title{
Quality of Obturation Achieved by Different Endodontic Obturation Systems
}

\section{Lidija POPOVSKA @, Marijana MIRCHESKA®, Tulin HAJREDIN@, Biljana GJORGJIEVA}

\begin{abstract}
Objective: This study was performed to determine in vitro the sealing ability of different endodontic obturation systems and to compare their efficacy.

Materials and Methods: In the study were used a total of 36 root canals all of which belong to extracted permanent teeth. Root canals of all samples were prepared with ProTaper Universal rotary files. The teeth were divided into four groups. In each group we had 1 molar with 3 canals, 1 molar with 2 canals, 1 premolar with 1 canal and 3 single-rooted incisors filled by different obturation technique and AH26 sealer. The teeth in the first group were obturated with single-cone technique, in the second group by cold lateral condensation, and the teeth in the third group were obturated with Thermafil. In the fourth group obturation was done with GuttaFlow. After radiography of the root canal fillings, the roots were sectioned horizontally at the level of $2 \mathrm{~mm}$ and $4 \mathrm{~mm}$ from the apex. The area of gaps and adaptation to canal walls were evaluated using stereomicroscopy and calculated.

Results: Evaluation of quality of obturation of root canals based on X-ray examination exhibited compact seal of root canals in all research groups, except with single-cone technique. Evaluation of cross sections revealed that lateral condensation showed the best hermetic sealing and the single-cone technique the worst. GuttaFlow and Thermafil have similar sealing effect.

Conclusion: It can be concluded that the density of guttapercha was observed to decrease towards the coronal aspect when the single cone and GuttaFlow were used.
\end{abstract}

Lidija Popovska (四)

Faculty of Dental Medicine, University of "Cyril and Methodius"in Skopje, North Macedonia. Address: "Naroden Front" 5/10 Skopje, North Macedonia e-mail:lpopovska@stomfak.ukim.edu.mk

Tulin Hajredin and Biljana Gjorgjieva

Faculty of Dental Medicine, University of "Cyril and Methodius" in Skopje, North Macedonia

Marijana Mircheska

Faculty of Dentistry, European University Skopje, North Macedonia

Reprint requests should be addressed to Professor Lidija Popovska.

Submitted / Gönderilme: 27.07.2020

Accepted/Kabul: 08.07.2021
Keywords: endodontic sealers, obturation technique, root canal obturation

\section{Introduction}

The last-but-not-least stage in endodontic therapy is the root canal obturation, which is provided by hermetic filling of the disinfected and shaped root canal system. This is confirmed by the fact that $60 \%$ of the failure of endodontic therapy is caused precisely by the incomplete obturation of the root canal (1). This fact underlines the importance to choose the right material and appropriate technique that will provide the required goal. The filling is usually done with a gutta-percha and cement. Our purpose should always be sealing the root canal completely in the lateral and vertical directions with the root canal filling material. This material should be stable in size and not shrink in the root canal. Furthermore, it should be bacteriostatic but at the same time should not irritate the vital tissue, should be insoluble, should not harden too quickly and should have radio-opacity. It should be easy to apply, but should also be easy to remove if necessary (2). But none of the techniques or sealers used nowadays meets all these requirements. That is why manufacturers of dental materials are still innovating new techniques and materials.

The most recommended filling material is polydimethylsiloxane-based cement filling such as GuttaFlow (Coltène/Whaledent AG, Altstätten, Switzerland) which combines silicon (3), with incorporated small particles of a gutta-percha in 1:1 ratio. It is used as a system which is filled with cold-but-liquid gutta-percha (2) and its application is a simple, safe and hygienic procedure, in accordance with ISO standards (4). The base of using this cement is that, it is considered to be biocompatible and it does not irritate vital periapical tissue (5). According to the manufacturer, this 
obturation system offers excellent physical properties because it does not contract after hardening and easily expands by $0.2 \%$, which increases the obturation ability. The material comes in capsules that are mixed in an ordinary amalgamator before use, applied to a carrier and then directly inserted into the prepared root canal by cannulas. Thus, determining the root canal filling quality using four different obturation techniques has been chosen as the aim of this study.

\section{Material and Method}

For the purposes of this study, we used a total of 36 root canals. After the trepanation of the pulp chamber, we determined the patency of the root canals and their working length with K-file. We inserted the K-file till the anatomical apical foramen. After the K-file has reached the same level with the anatomical apical foramen, we retracted $0.75 \mathrm{~mm}$ backwards. Thus we determined our working length. We did the canal instrumentation by ProTaper Universal rotary system with instruments S1, S2, F1, F2, F3 (Dentsply, Maillefer) and irrigation was performed with $3 \%$ sodium hypochlorite. After the instrumentation, we irrigated the root canal with $17 \%$ of EDTA to eliminate the smear layer. We finished with $5 \mathrm{ml}$ of saline, after which we divided the teeth into four groups each consisting of six teeth with nine canals in total, according to the filling of the canal. We filled the teeth of the first group with the classic single-cone technique. In the second group we used lateral condensation, and in the third we did the filling with Thermafil (Dentsply Maillefer, Switzerland). We used AH26 (Dentsply De Trey, GmbH, Konstanz, Germany) as a sealer for the first three groups. We did the root canal obturation in the fourth group with GuttaFlow, according to the manufacturer's instructions. The coronary part of all teeth was closed with a temporary cement (GJ Fuji) and then the samples were stored at $100 \%$ humidity for 30 days.

The assessment of quality of the canal filling was done as follows:

1. In order to estimate the degree of filling of the canals and its compactness, we made X-ray in two projections: bucco-oral and mesio-distal.

2. Stereomicroscopy was used with an increase of 16 times to determine the degree of fullness of the root canal at the level of the cross section. The cross sections were made at distances of $2 \mathrm{~mm}$ and $4 \mathrm{~mm}$ from the anatomical apex.

The obtained results were evaluated semi-quantitatively, with scores of $\mathrm{a}, \mathrm{b}$ and $\mathrm{c}$. Assessment $\mathrm{a}$ ) indicated complete canal fullness and good adaptation to the walls; b) meant the existence of small defects through the compact filling; and in the samples marked with c) a large part of the filling is missing and there are clearly visible empty spaces.

All specimens were evaluated by one rater (experienced dentist) on three different occasions at two days' intervals. The data used for further analysis were an average of the three estimates.

The data were statistically analysed with SPSS 23 for Windows (SPSS Inc., Chicago, IL, USA) with descriptive analysis. Chi-squared test was used to detect differences in the treatment outcomes (excellent, moderate, poor) related to the method of treatment. Statistical significance was defined as $\mathrm{p}<0.05$.

\section{Results}

The results obtained from radiographic images showed that root canal filling made with lateral condensation (Figure 1), Thermafil and GuttaFlow (Figure 2) provide a compact filling of the entire endodontic space. The X-ray of samples obturated with classic single-cone technique were of the lowest quality and most unequal (Figures 3 and 4). Buccooral projection could be assessed as more successful than in mesio-distal X-rays.

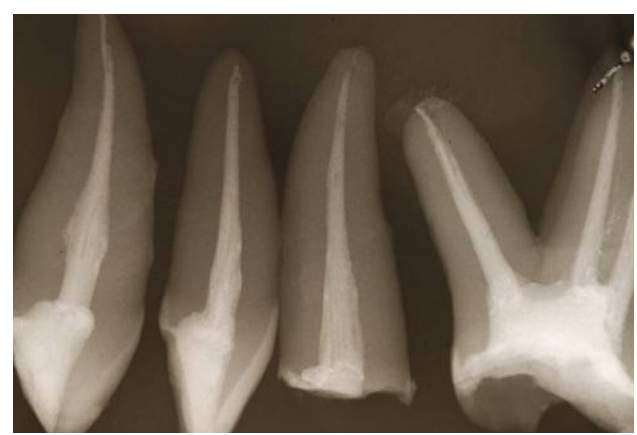

Figure 1. X-ray of teeth filled with lateral condensation.

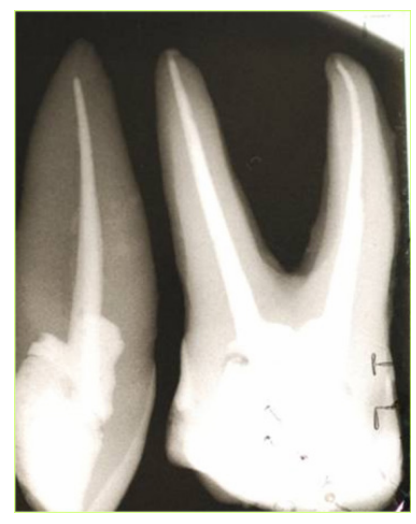

Figure 2. GuttaFlow-toothed tooth. 


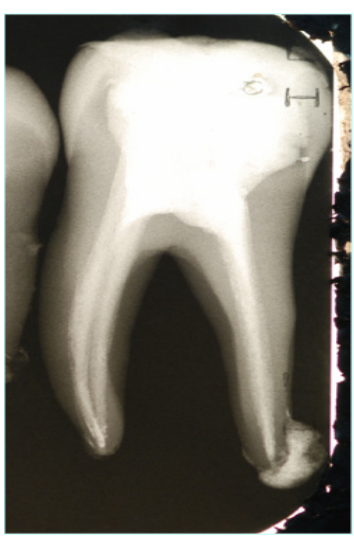

Figure 3. X-ray of a tooth filled with single-cone technique in the bucco-oral direction.

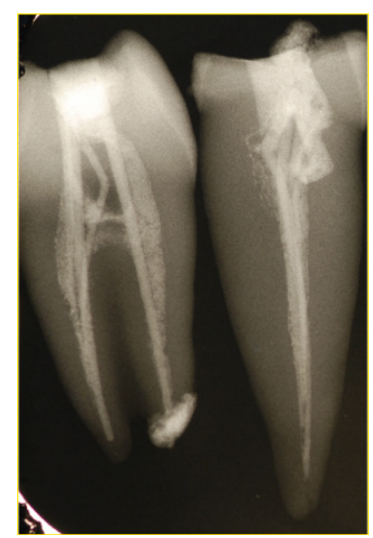

Figure 4. RTG recording of teeth filled with single-cone technique in mesio-distal direction.
According to the stereomicroscopic analysis, the most compact fillings showed the cross sections of the lateral condensation at both examined levels (Figure 5). Fillings with Thermafil and GuttaFlow have shown approximate quality of the obturation (Tables 1 and 2), where small cracks in Thermafil filling were always between the plastic carrier and the molten gutta-percha (Figure 6), while GuttaFlow filling in certain preparations showed small gaps, which was more evident on distance $4 \mathrm{~mm}$ from the apex (Figure 7). The fillings where the single-cone technique was used were the least compact, and in some sections during cement leakage only the gutta-percha points were observed in the root canal (Figure 8).

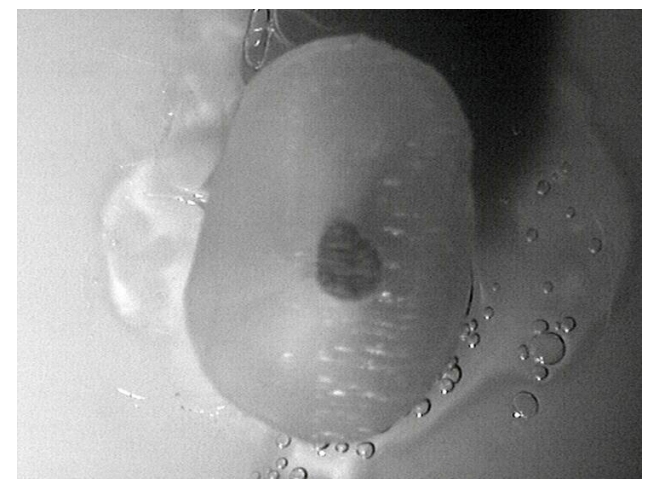

Figure 5. Cross section of $4 \mathrm{~mm}$ from apex in tooth filled with lateral condensation.
Table 1. Stereomicroscopic estimate for filling gaps through filling and adaptation of the material at a distance of $2 \mathrm{~mm}$ from the apex.

\begin{tabular}{llll}
\hline Type of filling & \multicolumn{3}{l}{$\begin{array}{l}\text { Cross section at a distance of } 2 \mathrm{~mm} \\
\text { from the apex }\end{array}$} \\
\hline Semi-quantitative assessment & a & b & c \\
\hline Single-cone & 4 & 4 & 1 \\
GuttaFlow & 5 & 4 & 0 \\
Thermafil & 6 & 3 & 0 \\
Lateral condensation & 8 & 1 & 0 \\
\hline
\end{tabular}

Table 2. Estimation of gaps in filling and adaptation of the material at a distance of $4 \mathrm{~mm}$ from the apex with an increase of 16 times.

\begin{tabular}{llll}
\hline Type of filling & \multicolumn{3}{l}{$\begin{array}{l}\text { Cross section at a distance of } 4 \mathrm{~mm} \\
\text { from the apex }\end{array}$} \\
\hline Semi-quantitative assessment & a & b & c \\
\hline Single-cone & 3 & 3 & 3 \\
GuttaFlow & 4 & 5 & 0 \\
Thermafil & 7 & 2 & 0 \\
Lateral condensation & 8 & 1 & 0 \\
\hline
\end{tabular}

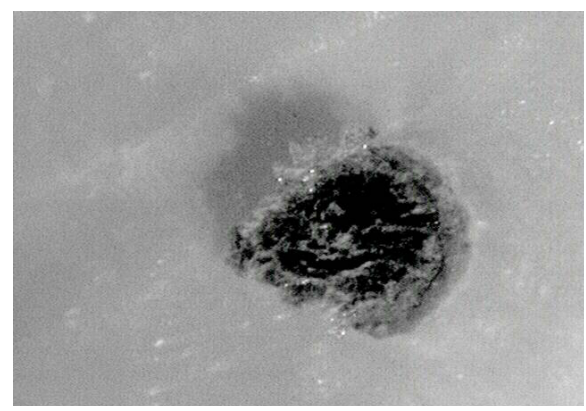

Figure 6. Cross section at a distance of $2 \mathrm{~mm}$ from apex in a tooth filled with Thermafil. It is visible a narrow gap between the carrier and gutta-percha.

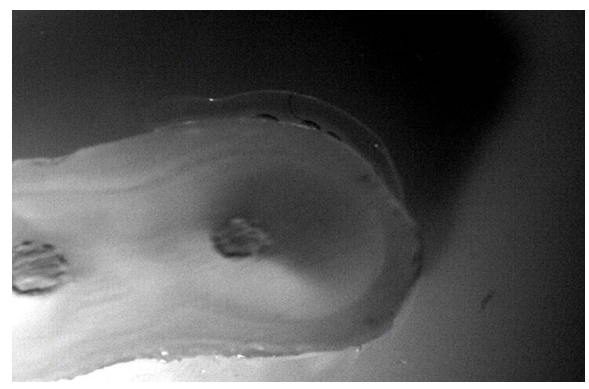

Figure 7. Cross section at a distance of $4 \mathrm{~mm}$ in a tooth filled with GuttaFlow. 


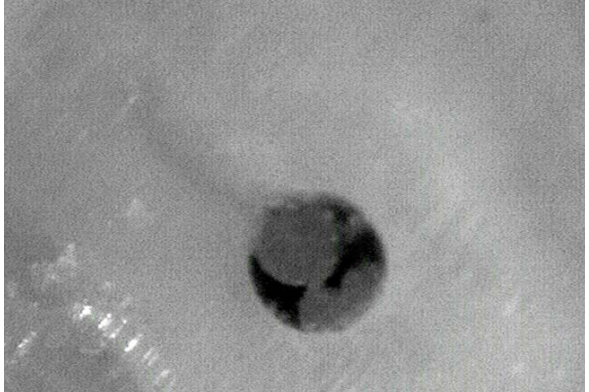

Figure 8. The empty spaces around gutta-percha are visible at a tooth filled with single-cone.

Between the specimens obtained by axial cross section at $2 \mathrm{~mm}$ above the apex of the tooth's root, the fourth method of treatment exhibited the most excellent outcomes with 8 of 9 specimens (88.9\%), compared to the third method with 6 of 9 (66.7\%), second method with 5 of 9 (55.6\%) and the first method with 4 of 9 (44.9\%) excellent outcomes (Table 3 ).

Table 3. Cross-tabulation of quality and methods for the specimens obtained by axial cross section at $2 \mathrm{~mm}$ above the apex of the tooths' root.

\begin{tabular}{|c|c|c|c|c|c|c|c|}
\hline & \multicolumn{4}{|l|}{ Method } & \multirow{3}{*}{\begin{tabular}{|l} 
Total \\
23
\end{tabular}} \\
\hline & & & $\mathrm{m} 1$ & $\mathrm{~m} 2$ & $\mathrm{~m} 3$ & $\mathrm{~m} 4$ & \\
\hline \multirow[t]{9}{*}{ Quality } & \multirow[t]{3}{*}{ excellent } & Count & 4 & 5 & 6 & 8 & \\
\hline & & $\begin{array}{l}\text { \% within } \\
\text { Quality }\end{array}$ & $17.4 \%$ & $21.7 \%$ & $26.1 \%$ & $34.8 \%$ & $100.0 \%$ \\
\hline & & $\begin{array}{l}\text { \% within } \\
\text { Method }\end{array}$ & $44.4 \%$ & $55.6 \%$ & $66.7 \%$ & $88.9 \%$ & $63.9 \%$ \\
\hline & \multirow[t]{3}{*}{ moderate } & Count & 4 & 4 & 3 & 1 & 12 \\
\hline & & $\begin{array}{l}\text { \% within } \\
\text { Quality }\end{array}$ & $33.3 \%$ & $33.3 \%$ & $25.0 \%$ & $8.3 \%$ & $100.0 \%$ \\
\hline & & $\begin{array}{l}\text { \% within } \\
\text { Method }\end{array}$ & $44.4 \%$ & $44.4 \%$ & $33.3 \%$ & $11.1 \%$ & $33.3 \%$ \\
\hline & \multirow[t]{3}{*}{ poor } & Count & 1 & 0 & 0 & 0 & 1 \\
\hline & & $\begin{array}{l}\text { \% within } \\
\text { Quality }\end{array}$ & $100.0 \%$ & $0.0 \%$ & $0.0 \%$ & $0.0 \%$ & $100.0 \%$ \\
\hline & & $\begin{array}{l}\% \text { within } \\
\text { Method }\end{array}$ & $11.1 \%$ & $0.0 \%$ & $0.0 \%$ & $0.0 \%$ & $2.8 \%$ \\
\hline \multirow{3}{*}{\multicolumn{2}{|c|}{ Total }} & Count & 9 & 9 & 9 & 9 & 36 \\
\hline & & $\begin{array}{l}\% \text { within } \\
\text { Quality }\end{array}$ & $25.0 \%$ & $25.0 \%$ & $25.0 \%$ & $25.0 \%$ & $100.0 \%$ \\
\hline & & $\begin{array}{l}\% \text { within } \\
\text { Method }\end{array}$ & $100.0 \%$ & $100.0 \%$ & $100.0 \%$ & $100.0 \%$ & $100.0 \%$ \\
\hline
\end{tabular}

Between the specimens obtained by axial cross section at $4 \mathrm{~mm}$ above the apex of the tooths' root, the fourth method of treatment exhibited significantly $(\mathrm{p}=0.02)$ the most excellent outcomes with 8 of 9 specimens $(88.9 \%)$, compared to the third method with 7 of 9 (77.8\%), second method with 4 of 9 (44.4\%) and the first method with 3 of 9 (33.3\%) excellent outcomes (Table 4).
Table 4. Cross-tabulation of quality and methods for the specimens obtained by axial cross section at $4 \mathrm{~mm}$ above the apex of the tooths' root.

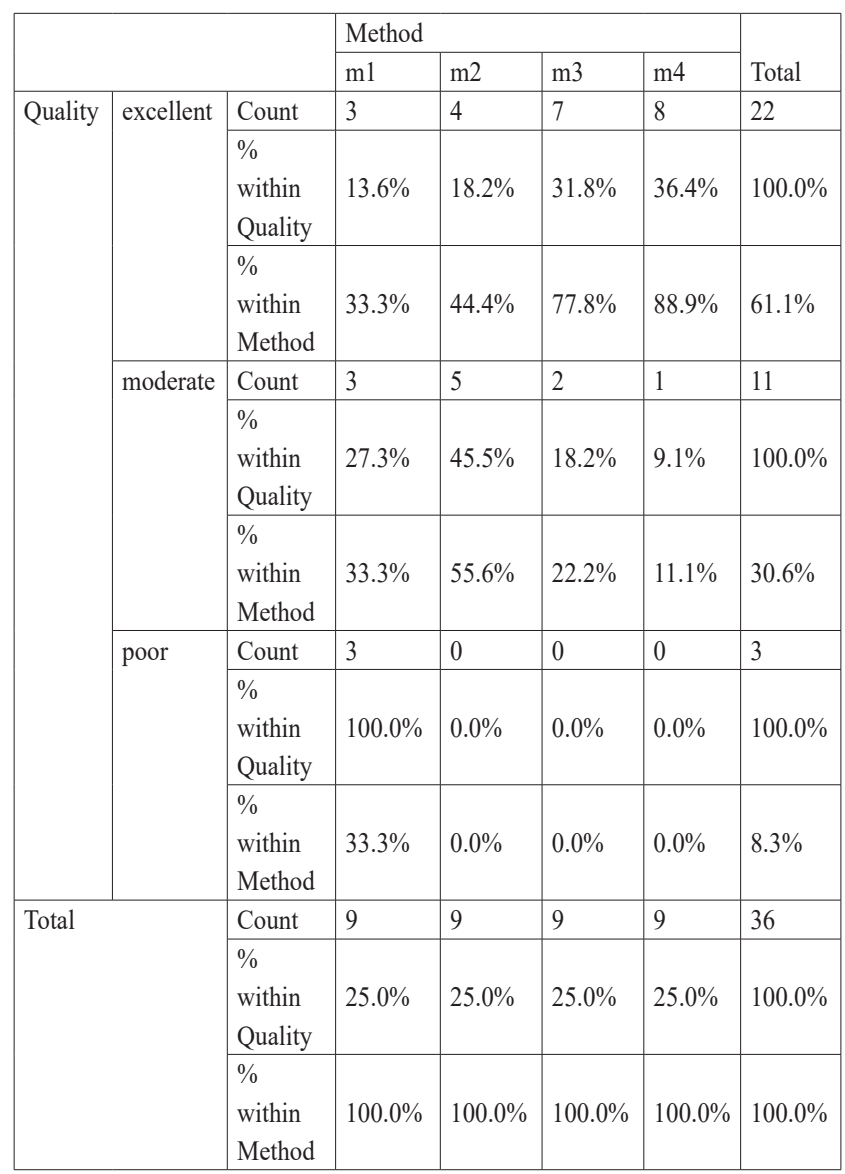

\section{Discussion}

Correct obturation is one of the main factors for successful endodontic therapy. If filling is not compact, the main problem is microleakage, which is a major factor in the failure of endodontic therapy. If there is stagnation of tissue fluid, proteolysis occurs, resulting in persistence of a periapical lesion or the formation of a new lesion around the tooth that has already been treated endodontically (6).

This study has been performed to compare the siliconebased cement filling method with other filling techniques. The comparison was made with the classic single-cone technique, which is still widely used, but also with other methods that have been shown to provide much more stable results. It is generally accepted in the professional literature that higher clinical success is achieved with fillings that have a higher percentage of gutta-percha and less cement (7). This method is not recommended for several reasons. 
The first problem is the ratio of cement to gutta-percha, with a large amount of cement making up the filling. Most of the cements are soluble, so over time the permeability increases (8). Furthermore, in the classic processing of the root canal with a cone size of $2 \%$, the filling procedure itself is unreliable, because the gutta-percha is easily distorted and retains the small irregularities in the canal. The standard gutta-percha that are used for this kind of filling are too soft and are intended more for other techniques that use compaction of the gutta-percha, such as lateral condensation. In our examination it was shown that the filling is with lower quality at cross sections of $4 \mathrm{~mm}$ compared to those of $2 \mathrm{~mm}$. We think the reason for this is that the preparation made with ProTaper Universal has a larger conicity than the four-percent-conic-gutta-percha that we used, so the diameter of the gutta-percha that corresponded to the apical was insufficient for the more coronal parts of the root canal. The result would probably be much better if we used guttapercha with the adequate conicity to the preparation.

Usually in clinical cases these fillings do not look so bad due to the anatomy of the root canals. The anatomicalmorphological characteristics of the canals are such that they are always wider in the bucco-lingual projection than in the mesio-distal, so that the filling defects overlap with the other parts $(2,9)$ which has been proven by this examination.

Obturation with Thermafil was done by the technique of a hot gutta-percha inserted with its own plastic carrier. The root canal is filled quickly and easily and the guttapercha penetrates all the lateral canals and irregularities. Many studies have been done on the quality of filling with Thermafil, which shown quite contradictory results for (11, 12) and against $(5,13)$ compared to lateral condensation. The results of our study showed that the filling with Thermafil was compact and that small cracks were observed only between the carrier and the gutta-percha. However, the ability of the gutta-percha to penetrate anywhere can be a problem, because if there is a wider apical foramen, the gutta-percha can easily leak into the periapical tissue (3). One of the disadvantages when using such a filling material in curved root canals is the plastic carrier's inclination to straighten. However, in our experience, in addition to the patient's discomfort, overheating is not a problem that has permanent consequences.

Lateral condensation is an obturation technique that provides hermetic root canal sealing. This technique is the most widely used obturation method in endodontics. About
$89.6 \%$ of dental faculties around the world teach it as a primary or classical technique (14). The main material for filling the root canal is gutta-percha. Due to its good results, this technique is often used for comparison when examining other methods of obturation. Our stereo microscopic images showed that this group was the most successfully filled and that in root canals there is no empty space left according to the possibilities of our examination.

GuttaFlow obturation is recommended as a simple method similar to the classic single-cone method. The application system provides the possibility for aseptic root canal obturation without the risk of secondary infection. The mixed material is soft and hardens within 7-10 minutes. This allows the material to penetrate all irregularities in the root canal system (15). Although Pitout et al. (16) and Monticelli et al. (17) have found that GuttaFlow fillings are just as successful as lateral condensation obturation, according to our results, although on X-rays the filling was rated as ideal, stereomicroscopic sections of certain preparations were observed small gaps through the filling that were at the level of the cement. These results in accordance with the findings of Elayouti et al. (6) and Malić et al. (15), who also detect these small cracks in the material.

Kontakiotis (9), examined the permeability of root canals filled with GuttaFlow and lateral condensation immediately after filling and after 12 months. His findings showed that after 12 months, teeth filled with GuttaFlow provided better obturation compared to others that were filled with the other method. He explained this finding with the expansion of the cement that improved the filling $(9,18)$. Bouillaguet et al. (1) did not confirm a difference in microleakage in teeth filled with this material 24 hours and one year after filling.

\section{Conclusion}

According to the results of this study, but also according to the data from the literature, it can be concluded that GuttaFlow as a filling material has incomparably better characteristics than any other cement used for definitive filling of the root canals. The teeth filled with this material showed much more successful final results than the filling with the single-cone technique with the usual endodontic cement. If this material was used with another technique, such as lateral condensation, then the quality of the filling would probably be closer to perfect.

The obturation quality of the GuttaFlow, even when it is used with the single-cone technique, is similar to the other 
two techniques, which have been improved to provide much better optical root canal obturation.

\section{References}

1. Bouillaguet S, Shaw L, Barthelemy J, Krejci I, Wataha JC: Long-term sealing ability of Pulp Canal Sealer, AH-Plus, GuttaFlow and Epiphany. Int Endod J. 2008;41(3):219-226. DOI:10.1111/j.1365-2591.2007.01343.x.

2. Capík S, Štvrtina J: Comparison of Gutta-Percha Obturation Techniques in the Treatment of Wide Root Canals in Dogs. Acta Vet. Brno 2008, 77: 291-296

3. Clark DS, ElDeeb ME: Apical sealing ability of metal versus plastic carrier Thermafil obturators. J Endod. 1993;19(1):49. DOI:10.1016/S0099-2399(06)81032-0.

4. Cohen S, Burns RC: Pathways of the Pulp, $7^{\text {th }}$ edition. Mosby, 1998.

5. De Moor RJ, De Bruyne MA: The long-term sealing ability of AH-26 and AH-PLUS used with three guttapercha obturation techniques. Quintessence Int. 2004;35(4):326-331.

6. Ingle JI, West JD: Endodontics, $4^{\text {th }}$ edition. Lea \& Febiger, 1994.

7. Elayouti A, Achleithner C, Löst C, Weiger R: Homogeneity and Adaptation of a New Gutta-Percha Paste to Root Canal Walls. J Endod. 2005;31(9):687-690. DOI:10.1097/01. don.000.015.7991.83577.e0.

8. Zielinski TM, Baumgartner JC, Marshall JG: An evaluation of Guttaflow and gutta-percha in the filling of lateral grooves and depressions. J Endod. 2008;34(3):295-298. DOI:10.1016/j.joen.2007.12.004.

9. Kontakiotis EG, $\mathrm{Wu} \mathrm{MK}$, Wesselink PR: Effect of sealer thickness on long-term sealing ability: a 2-year follow-up study. Int Endod J. 1997;30(5):307-312. DOI:10.1046/ j.1365-2591.1997.00087.x.

10. Tanomaru-Filho M, Torres FFE, Chávez-Andrade GM, de Almeida M, Navarro LG, Steier L, Guerreiro-Tanomaru
JM: Physicochemical Properties and Volumetric Change of Silicone/Bioactive Glass and Calcium Silicate-based Endodontic Sealers. J Endod. 2017;43(12):2097-2101. DOI:10.1016/j.joen.2017.07.005.

11. Siqueira JF Jr, Rôças IN, Favieri A, Abad EC, Castro AJ, Gahyva SM: Bacterial leakage in coronally unsealed root canals obturated with 3 different techniques. Oral Surgery, Oral Medicine, Oral Pathology, Oral Radiology, and Endodontics. 2000 Nov;90(5):647-650. DOI: 10.1067/ moe.2000.110412.

12. Wolcott J, Himel VT, Powell W, Penney J: Effect of two obturation techniques on the filling of lateral canals and the main canal. J Endod. 1997;23(10):632-635. DOI:10.1016/ S0099-2399(97)80176-8.

13. Ravanshad S, Torabinejad M: Coronal dye penetration of the apical filling materials after post space preparation. Oral Surg Oral Med Oral Pathol. 1992;74(5):644-647. DOI:10.1016/0030-4220(92)90359-x.

14. Whitworth J: Methods of filling root canals: principles and practices. Endodontic Topics. 2005;12(1):2-24. DOI: 10.1111/j.1601-1546.2005.00198.x.

15. Malić I, Miletić I, Pezelj-Ribarić S, Blazić-Potočki Z, Anić I: Propusnost punila Apexit Plus i GuttaFlow. Acta Stomatol Croat. 2008;42(2):140-146.

16. Pitout E, Oberholzer TG: Leakage of teeth root-filled with GuttaFlow and a single GP cone compared to lateral condensation and warm vertical condensation. SADJ. 2009;64(3):104-108.

17. Monticelli F, Sword J, Martin RL, Schuster GS, Weller RN, Ferrari M, Pashley DH, Tay FR: Sealing properties of two contemporary single-cone obturation systems. Int Endod J. 2007;40(5):374-385. DOI:10.1111/j.13652591.2007.01231.x.

18. Eldeniz AU, Ørstavik D: A laboratory assessment of coronal bacterial leakage in root canals filled with new and conventional sealers. Int Endod J. 2009;42(4):303-312. DOI:10.1111/j.1365-2591.2008.01509.x. 